\title{
The Nature of Volunteered Geographic Information
}

\author{
Cristina Capineri \\ Dept. of Social, Political and Cognitive Sciences, University of Siena, \\ cristina.capineri@unisi.it
}

\begin{abstract}
This contribution starts from the assumption that volunteered geographic information is a technological, cultural and scientific innovation. It therefore offers first some general background on the context that has fuelled the development of VGI and the lively scientific debates that have accompanied its success. The paper then focuses on the nature of this data by describing the main elements of VGI: the geographical reference (coordinates, geotag, etc.), the contents (texts, images, etc.) and the producers' profiles. The opportunities and the criticalities offered by this data are described with examples drawn from recent literature and applications to highlight both the research challenges and the current state of the subject. The chapter aims to provide a guide to and a reference picture of this rapidly evolving subject.
\end{abstract}

\section{Keywords}

volunteered geographic information, crowdsourced information, geography

\section{Introduction: a technological and cultural innovation.}

The most cited and debated definition of volunteered geographic information was coined in 2007 by Michael Goodchild (2007) as a subset of user-generated content which carries specific spatial and temporal components:

\section{How to cite this book chapter:}

Capineri, C. 2016. The Nature of Volunteered Geographic Information. In: Capineri, C, Haklay, M, Huang, H, Antoniou, V, Kettunen, J, Ostermann, F and Purves, R. (eds.) European Handbook of Crowdsourced Geographic Information, Pp. 15-33. London: Ubiquity Press. DOI: http://dx.doi.org/10.5334/bax.b. License: CC-BY 4.0. 
'the widespread engagement of large numbers of private citizens, often with little in the way of formal qualifications, in the creation of geographic information, a function that for centuries has been reserved to official agencies. [..] I term this volunteered geographic information (VGI), a special case of the more general Web phenomenon of usergenerated content'(p.2).

Since 2007, the appeal of VGI has grown steadily and created a wide scientific community involved in the harnessing of these new sources of geographical information and in satisfying the spatial shift fuelled by the neogeography revolution which has put mapping within the grasp of almost any user who is not only in possession of suitable technology (e.g. a smartphone), but is capable of configuring it in order to capture location and skilled enough to view the resulting information and share it in space or on a map (Turner 2006; Batty 2010; Wilson \& Graham 2013).

All historical transformations in means of communication have led to a redefinition of lifestyles, of time and space which are deeply connected in society: their meaning, perceptions and manifestations are linked to social practices and evolve throughout history and across cultures. The transformations addressed here refer both to the development of Web 2.0 technologies and the diffusion of sensors of different types which have profoundly modified the ways of accessing, producing, diffusing and representing geographic information: 'This is an unprecedented moment in human history: we can now know where nearly everything, from genetic to global levels, is at all times" (Sui \& Delyser 2013: p.13).

In this sense VGI may be considered a significant innovation and as with any other innovation it combines technology, social practices and power relationships. First, the technology relies on the many location-based devices used potentially by ordinary citizens who become sensors and on Web 2.0 applications which enable information co-creation (social media, photo-sharing platforms, wiki projects, etc.) in huge quantities. Secondly, the phenomenon of user-generated content is part of a cultural change which very recently has led to the adoption of open access and a collaborative and sharing approach to information resources. This cultural turn has been defined as collective intelligence by the French philosopher Pierre Levy (1994) who explains that the collective intelligence tries to articulate in a new way the individual and the collective domains in a new space of knowledge'. This concept has also been discussed by Manuel Castells $(1996,2008)$ who has explained that in the information age there is a growing juxtaposition of individualism and communalism: networks of individuals which provide the basis for increasing our sociability as individuals. In sociological studies many argue that the 'bond of community' has been lost (Putman 1995) and that there is a need to improve and rebuild social capital; in this sense the debate on the contribution of social 
media to social capital building is questionable. It is hard to imagine how largescale social movements and community building activities can be organized effectively on the basis of qualitative practices alone, as the logistical challenge requires an ability to plan schedules, develop strategies and master communications technologies: certainly the burgeoning relationships through social media betray new communication and social practices. Furthermore, the accelerated deterritorialization process implies the removal of barriers and limits but also the restoration of stronger social ties.

Indeed the participative and collaborative approach is emerging in contemporary society as Jeremy Rifkin (2011) explains: 'people are biologically predisposed to be empathic - that our core nature is not rational, detached, acquisitive, aggressive, and narcissistic, but affectionate, highly social, cooperative, and interdependent. Homo sapiens is giving way to Homo empathicus'. Historians tell us that empathy is the social glue that allows increasingly individualized and diverse populations to forge bonds of solidarity across broader domains so that society can cohere as a whole.

In this context the crowdsourcing process has emerged and has been defined by the journalist Jeff Howe (2008) as 'the process by which the power of the many can be leveraged to accomplish feats that were once the province of a specialized $f e w$ '. This phenomenon has been supported by the so-called 'sharing economy' as a socio-economic system built on the sharing of skills, goods and services driven by the increasing sense of urgency of resource depletion; by the open source movement which - at least in theory - enables any user to participate in the information society by sharing know-how and skills mediated by Web 2.0 tools and applications. Famous initiatives like Wikipedia, founded in 2001 or, more specifically in the realm of geography, OpenStreetMap, launched in 2004, do not need any further explanation here.

VGI is thus closely related to the concept of crowdsourcing as it is an assertive method of collecting geospatial information from people who are mainly participating in Web-based social networking sites, in citizen science initiatives or in the context of collaborative commons-based peer production networks (Benkler \& Nissenbaum 2006).

The volunteering element is the subject of debate in VGI literature since contributors may produce information either consciously or unconsciously: crowdsourcing implies a process of consensus production whereby many people will provide and augment information about the same thing which will become more and more accurate thanks to a convergence of information. In the case of geographic information involuntarily produced by individuals, quality might be debated since data are often collected publicly without strict standardization and every user inserts data according to his/her personal background and point of view (Coleman 2009). In fact Harvey (2013) has suggested the definition crowdsourced geographic information which refers to data collected via 'opt-out' agreements which are more open-ended and offer fewer 
opportunities to control the data collection, and subsequently its quality and assessment. In contrast, when volunteered information production - or geographic volunteer work (Priedhorsky et al. 2010) - is regulated by shared rules concerning the geocoding, tagging and annotation of the data, VGI becomes part of citizen science. Citizen science has emerged from the fields of ecology, biology and nature conservation, whose projects are based on volunteering and contribution of information on areas such as biodiversity, environmental quality or endangered species both for the benefit of human knowledge and science (Haklay 2013a). This is demonstrated by the countless applications in the field of biodiversity monitoring and environmental assessment (Bonney et al 2009; Gouveia et al. 2008) as emerging problematic issues in the context of sustainable development.

Citizen science re-evaluates the separation between scientists and public, and scientists need to adjust to their new role as mediators of knowledge rather than as the sole repository of scientific truth: 'This might end up being the most important outcome of citizen science as a whole as it might eventually catalyse the education of scientists to engage more fully with society' (Haklay 2013:14).

In this context VGI embodies either the implicit or explicit relationship of the individual to the world and represents the sense of belonging, in some intrinsic way, to a larger body, whether a nation or a neighbourhood; this relationship has long been a critical part both of the individual's motivation to act in some larger interest and of the group's ability to exhort the individual to take action and participate (Curry 1997).

Before closing this introductory section, it is worth mentioning that literature related to VGI has increased enormously in the recent past (see the Introduction of this Handbook) which may lead us to ask why VGI is so appealing and why it has created so much scientific interest in geography. The main drivers of its success certainly relate to:

a) the features of this information (the non-expert producers, the participatory approach, the huge quantity, the real time accessibility, the finergrained resolution and the scalability);

b) the extremely diversified fields of potential applications (disaster and crisis management, environmental monitoring, planning, land use, mobility, people's behaviour etc.) which are more and more employed in governance and in the management of public services;

d) the 'wow' component due to unexpected, creative and sometimes amusing topics which can be tackled spatially with these sources. This is well demonstrated by the Floatingsheep collective which started in 2009 by producing witty and entertaining explorations such as Santa Claus's homeland, the 'beer belly' of America, zombies $v s$ vampires and so on: 'At FloatingSheep, we're willing to search for and analyse almost anything that falls within the realm of human experience. Sometimes this is mundane 
(pizza) and sometimes it is contentious (abortion) but most of the time it falls somewhere in between. Such as, where can I get a drink?';

e) the experiential and perceptional nature of the content embedded in VGI which can be distilled both to achieve a better understanding of beliefs, practices and habits and potentially challenge the dominant narratives, because VGI is built on the understanding of the social world mediated by people's conversations and contributions, thus it consists of social practices (Elwood 2008).

\section{The components of VGI}

Generally speaking VGI consists of a 'big' and ongoing flow of data deriving from different tools and media (mobile phones, cameras, records of smartcard transactions, social platforms, check-ins, location-based devices, etc.); they are digital footprints, or data shadows, or by-products of human/machine interactions (Graham 2013). Such digital footprints are produced by anyone who may potentially act as a sensor and provide, more or less consciously, valuable information (Capineri \& Rondinone 2011; Haklay et al. 2008; Sui 2008) by applying local and sectorial knowledge since producers are '[...] equipped with some working subset of the five senses and with the intelligence to compile and interpret what they sense, and each free to rove the surface of the planet' (Goodchild 2007).

More precisely the essential components of VGI are:

1) the geographical references (i.e. geotag, coordinates, geographic name) which enable the information to be represented on a map and thus satisfy the eternal human desire to know 'where we are' or 'where things are';

2) the stock of content which makes it possible to transform this data into information and possibly knowledge. The content may take different forms: images, texts, symbols, maps, check-ins, photos, videos, drawings, etc.

3) attributes, of various degrees of accuracy, of content users and content producers (produsers, Coleman et al. 2009) (such as nationality, language and possibly age and gender) and the time of the digital footprint's creation.

The combination of three components provides a powerful way to aggregate, synthesize and compare information at different scales on specific issues or events which are occurring either in real time or in longer time spans.

Thus VGI components may be represented as the three corners in a standard ternary diagram (Figure 1) to show that employment of this data may vary according to the emphasis given to one or more of the components or to the

\footnotetext{
1 www.floatingsheep.org.
} 
1.Where / Location Spatial perspective

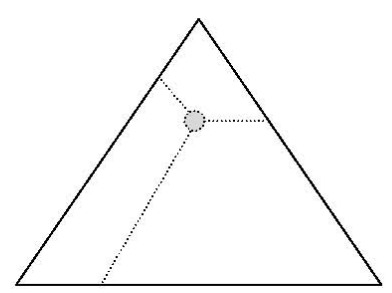

2.What/content Place perspective

3. Who/prosumers Participation, motivation, community of interests

Figure 1: VGI, a diagram representation of the components.

changing balance between, for example, ecological, spatial or regional synthesis. The corners represent the components and the related perspectives: (1) the where of the information given by the geographical reference which serves a spatial perspective, (2) the what given by the stock of content which suits placeoriented and qualitative analysis, (3) the who given by the produsers which fits well the analysis of the participation and production process. The barycentre's position represents the different composition of the three VGI components and it may vary according to the chosen perspective.

Of course the representation is oversimplified since at least the time dimension needs to be added to give a fuller picture of the potentialities of the relationship between the components of VGI sources. Moreover the complexity of VGI data lies in the fact that analysis needs to draw on cognitive, psychological and anthropological inputs to fully appreciate and exploit this data, thus going beyond simple representation on a map. The fragmented individual-level contents from the crowd provide qualitative information which was unreachable in the past through traditional direct investigations (i.e. surveys, interviews, etc.) or official data (i.e. census); the employment of qualitative information is not new in geography, as it was the pillar of the perception and behavioural approach (Claval 1974), but the innovative aspects are, in addition to the quantity and the scale (from global to local and vice versa), the granularity of the topic and the timeliness that VGI allows. As Table 1 shows, very specific events or unexpected topics, like beverage-consumption habits, can be now quite easily addressed and explored.

In the following sections each of the components will be briefly discussed drawing examples both from existing literature and my own research. 


\begin{tabular}{|c|c|c|c|}
\hline Event-dependent & Activity time & $\begin{array}{l}\text { User generated } \\
\text { contents }\end{array}$ & Scale \\
\hline $\begin{array}{l}\text { Habemus Papam } \\
\text { (Source:Ladest) }\end{array}$ & 13-14 March 2013 & $\begin{array}{c}\text { 10,000 Geocoded } \\
\text { Tweets }\end{array}$ & Global \\
\hline $\begin{array}{l}\text { Palio di Siena } \\
\text { (Source:Ladest) }\end{array}$ & 01-02 July 2013 & $\begin{array}{c}375 \text { Geocoded } \\
\text { Tweets }\end{array}$ & Urban \\
\hline $\begin{array}{l}\text { Hurricane Sandy in NYC } \\
\text { (Source: Shelton et al. 2014) }\end{array}$ & 24-30 October & $\begin{array}{c}\text { 16,000 Geocoded } \\
\text { Tweets }\end{array}$ & Urban \\
\hline \multicolumn{4}{|l|}{ Topic-oriented } \\
\hline $\begin{array}{l}\text { Church or Beer } \\
\text { (Source: FloatingSheep) }\end{array}$ & 22-28 June 2012 & $\begin{array}{c}17,686 \text { (church) }+ \\
14,405 \text { (beer) }\end{array}$ & National \\
\hline
\end{tabular}

Table 1: Some examples of event-dependent or topic-oriented applications in VGI.

\section{The geographical reference: living space and local knowledge}

The geographical component represents the raw digital footprint that can be represented in space as the manifestation of the producers' activity - or inactivity - on the Web. Although the act of producing information is to a greater or lesser degree voluntary, locating the origin of this data on the Earth's surface highlights the constellations of participation on the Web thanks to geocoding attributes (geotags; geographic names, coordinates). The footprints offer a preliminary source of information which reveal the produsers' appropriation of place by naming, tagging or annotating it.

The geographical component has a phenomenological value in itself since it is often a response to a stimulus, either an event or a simple desire to get in touch with friends and show where you are or where you have been. Many case studies show strong uneven geographical patterns of participation in the production of VGI which may be described through the digital divide metaphor (Graham 2014). The divide may be caused by different reasons such as the uneven diffusion of the technology but also the ability to work with or benefit from it. The distribution of geotagged Wikipedia articles (Figure 2) supports this assumption. The articles on Wikipedia are an example of pure volunteered geographic information because users have added content in Wikipedia deliberately, and despite the pervasiveness of the internet, recent analysis shows that the practice of producing content is mainly concentrated in the United States, Western Europe, Japan and in some emerging countries in South America and Asia. The uneven distribution is mainly explained by the traditional variables of wealth such as population, GDP per capita and broadband internet connections (Graham et al. 2014). 


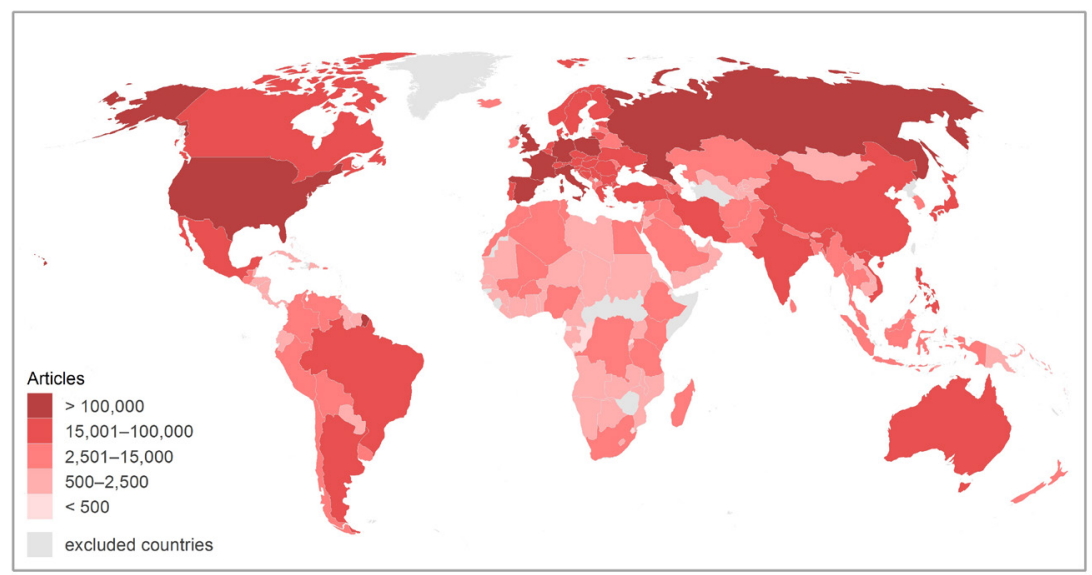

Figure 2: Geotagged Wikipedia articles per country in all languages (Source: Graham et al. 2014).

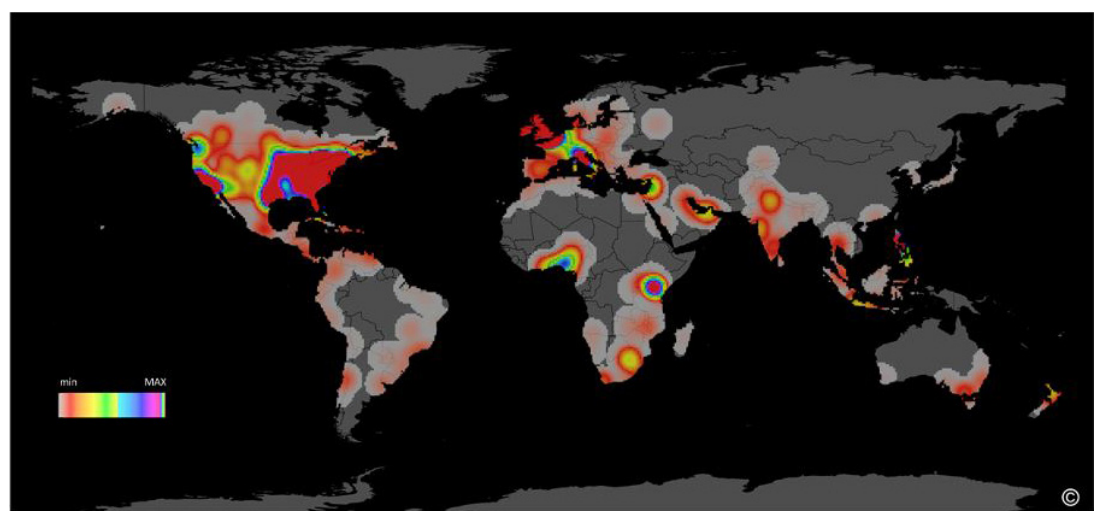

Figure 3: Habemus Papam: Tweeting activity on the Pope's election day (Source: Ladest \& Unisi 2013).

When dealing with crowdsourced information derived from social media, other types of uneven distribution may emerge. The map (Figure 3) showing the Tweets sent about the election of Pope Francis in March 2013 (10,000 Tweets collected on 13-14 March 2013) is an expression of a heterogeneous community of interest which has spontaneously responded to a particular event, unaware of the fact that their Tweets might be collected and analysed: here the uneven distribution appears smoother than Wikipedia's divide due to the religious or political appeal that the Pope's election may have (note the intense activity in the Arab Gulf and in Western Africa).

This uneven participation pattern on the Pope's election day requires further investigation in order to discover the reasons for such disparities, which could 
include critical aspects of religious beliefs and cultural proximity: the Pope's election map is a manifestation of an event-related social activity which has converged on the election of Pope Francis and will soon fade away. The uneven participation in Wikipedia, which is a long-standing project, is more concerning than that described by the Pope's election map since it highlights a consolidated process of information production which reproduces well-known dichotomies (North-South; developed-less developed): so the apparent democratisation of information and knowledge remains debatable (Haklay 2013b).

Nevertheless, the great innovation is that this data enables us to locate spatially practices and topics (especially cultural and political ones) pertaining to people's everyday lives which reflect specific time-space configurations at different scales and with a degree of fine resolution which was impossible in the past.

From a methodological point of view, the location of the information may be questionable since georeferencing creates many ambiguities: (a) the same name may be used for more than one location, (b) the same location can have more than one name and (c) place names can be used in non-geographic contexts such as organizations, events or personal names. Furthermore, the greater or lesser awareness of the produsers' in the information generation process may affect accuracy and quality: while prosumers participating in citizen science activities adopt and share recording rules, unaware citizens just use the technologies for their own purposes and do not generally pay attention to the georeferencing of the information, despite adding relevant content. For example, if we search for 'Chianti', the famous wine-producing area in Tuscany, on Flickr, among the photos there is one of the bronze sculpture of Perseus with the head of Medusa by Benvenuto Cellini which is located near the Uffizi in Florence: ${ }^{2}$ in this case the tag 'Chianti' does not enable us to place the photo in the correct location but nevertheless it offers other hints relevant to a place-based analysis: indeed 'Chianti' is one of the many tags of this picture (Florence, wine, holiday, Stendhal Syndrome, lovely city, Arno river) which are employed by the user to describe the spirit of his/her Tuscan holiday experience.

\section{The stock of contents: place and qualitative information}

The content reveals the 'sticky places' in the fluid information flows: a world of places of knowledge which not only tell stories of VGI 'birthplaces' but collect the added value generated by the produsers. Contents may be either 'neutral/locational' if carrying simply positional information (i.e. an address) or descriptive if they take the form of texts, comments, images, drawings or video clips. The stock of contents records points of view, values, feelings, expressions of appreciation or contempt, of happiness and unhappiness; in short they

\footnotetext{
${ }^{2}$ https://www.flickr.com/photos/75992994@N05/15607974697/in/photolist-pMdX72-pkvq8o6JxVtE-4WVhxs-5W7cNo-78kME8-sjwVKi [Accessed April 2016].
} 
represent the 'sense of place' engineered by the Web because VGI contributors are engaged in knowledge production processes which are grounded in social structures and sets of values, and in turn, physical place (Hardy et al. 2012: 3; Lussault 2007).

From this point of view, VGI content capitalizes the informal knowledge of the producers and becomes a collector of multiple identities and perceptions which highlight the variegated relationships with a certain place such as inclusion and exclusion, sharing and reacting and so on.

It is true in fact that VGI content incorporates the situatedness of individuals and the invisible knowledge of the producer, the location and the fluidity of perceptions (Zook \& Graham 2007).

The number of content contributors combined with the ability to annotate place in the geoweb may result in dense layers of information augmenting some parts of the world which describe 'the indeterminate, unstable, context dependent and multiple realities brought into being through the subjective comingtogethers in time and space of material and virtual experience" (Graham et. al. 2012: 465; Graham, Zook \& Boulton 2013). Several scholars (Graham 2010; Crang 1996) use the metaphor of palimpsests, with reference to medieval writing blocks that could be reused while maintaining traces of earlier inscriptions: 'the countless layers of any place come together in specific times and spaces and have bearing on the cultural, economic, and political characteristics, interpretation and meaning of a place"' (Graham 2010: 422).

For example, when reading the English and Farsi versions of the description of the town Esfahan in Iran on Wikipedia, the information is slightly different both in terms of the images shown and of content: the English version has more stereotyped pictures of the town's blue and white ceramic decorations than the Farsi version, which also contains descriptions of local artefacts. In addition, the nuclear activity which takes place close to the city is omitted in the Farsi version since the topic is clearly regarded as a sensitive one.

In this way crowdsourced information becomes particularly relevant in the production and acquisition of local knowledge either through place names or practices and values. People's contributions in VGI tend to be more accurate in places the contributor knows best and is nearer to, in accordance with Tobler's law which states that 'everything is related to everything else but near things are more related than distant things"' (Tobler 1970). As such, some literature hypothesizes that (a) contributors write about nearby places more often than distant ones and that (b) this likelihood follows an exponential distance decay function (Hardy et al. 2012). Indeed, according to recent research, about 50 percent of Flickr users contribute local information on average, and over 45 percent of Flickr photos are local to the photographer (Hecht \& Gergle 2010). Local knowledge deriving from VGI has remarkably been applied to vernacular geography, which had been eroded by the quantitative approach, which 'encapsulates the spatial knowledge that we use to conceptualize and communicate about space on a day-to-day basis. Importantly, it deals with areas which 
are typically not represented in formal administrative gazetteers and which are often considered to be vague"' (Hollenstein \& Purves, 2005: 22) such as 'downtown"' (Hollestein \& Purves 2010), 'neighbourhood'3 or regions like the 'Alps"' (Purves \& Derungs 2015) from the tags associated with georeferenced images and place marks.

\section{The urban character}

The settings of VGI are mainly urban: most of the crowdsourced information especially if derived from social media platforms - is produced in urban areas which combine connection facilities (internet, free $\mathrm{WiFi}$, hotspots etc.) and the concentrated critical mass of city users (residents, tourists, business people, commuters, students, visitors, etc.).

A recent study (Hecht \& Stephens 2014) reveals that in the US there are 3.5 times more Twitter users per capita in core urban counties than rural counties; the same authors have discovered that urban users Tweet more than their rural counterparts.

The following image (Figure 4) shows the relationship between Twitter activity at night and large urban areas in Italy (2013): $52 \%$ of the georeferenced Tweets (12,000 collected in one night) fall within the boundaries of the Italian large urban zones (LUZ), as defined by EUROSTAT; the percentage would be higher if the peri-urban areas were included.

VGI has been used in interesting ways in spatial analysis of cities' urban structures. In fact, recent research has identified 'natural cities' as human settlements, or human activities in general on the Earth's surface, that are delineated from massive geographic information derived from geocoded social media data (Jiang \& Liu 2012; Jiang in this book). The interesting aspect of this approach is that the employment of crowdsourced information allows us to see how cities evolve and change over time, even if the changes may simply refer to the espace véçu (living space) by city users. Here is an example of Jiang's methodology applied to Florence (Italy) which shows the concentration changes of geocoded Tweets for six months (May-October 2013).

VGI has contributed to the discovery of other urban issues. For example, analysis of geolocated Flickr photos has identified the most attractive spots or intra-urban tourist routes (Girardin et al. 2008) and discovered that foreigners privilege stereotyped places mainly concentrated in the city centre or at transport nodes (airports, stations) while local people's gaze seems to fall on less central locations (Crandall et al. 2009; Straumann et al. 2014).

If the annotations (comments, texts) of crowdsourced data are taken into account, narratives about urban settings may be constructed and may vary according to whether they are produced by insiders or outsiders. The following

\footnotetext{
${ }^{3}$ See http://livehoods.org/.
} 
table (Table 2) attempts to show the different qualitative narratives about London's attractions which emerge from different VGI sources. The table has been created by selecting the 10 most cited attractions on TripAdvisor and the 10 most frequently used hashtags on the Twitter account @Londonist; it highlights the sites mentioned, the related attributes and the meaning which can be ascribed. TripAdvisor's posts are generally created by outsiders (or tourists) and highlight the persistence of global imagery and the grandeur ideal of certain monuments which are at the base of a model of collective knowledge which endlessly reproduces itself over time (Raffestin 1988). In contrast, the most used hashtags from the profile @Londonist may be considered the
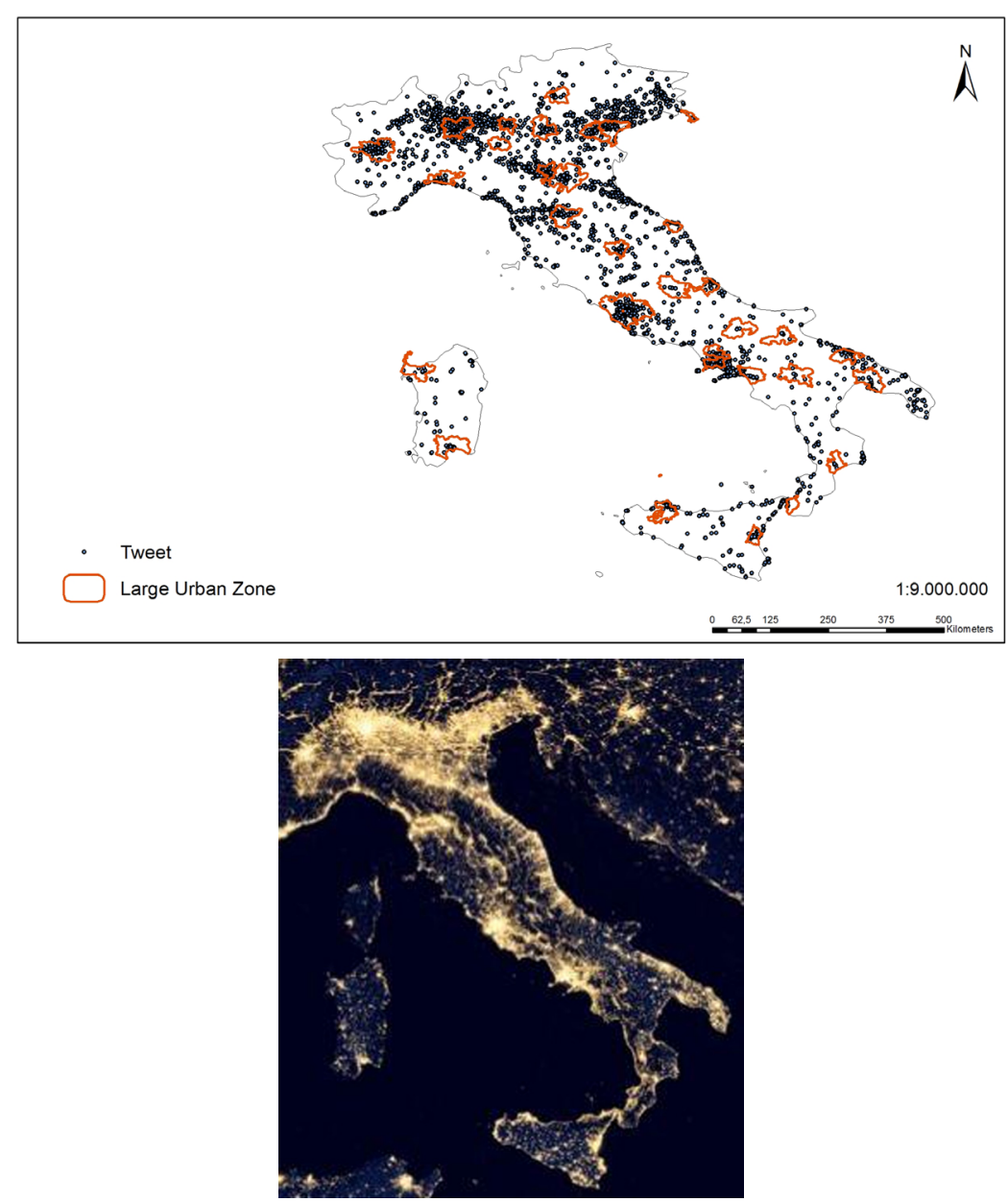

Figure 4: A comparison between Tweets sent at night and large urban zones in Italy (Source: Ladest 2016). 

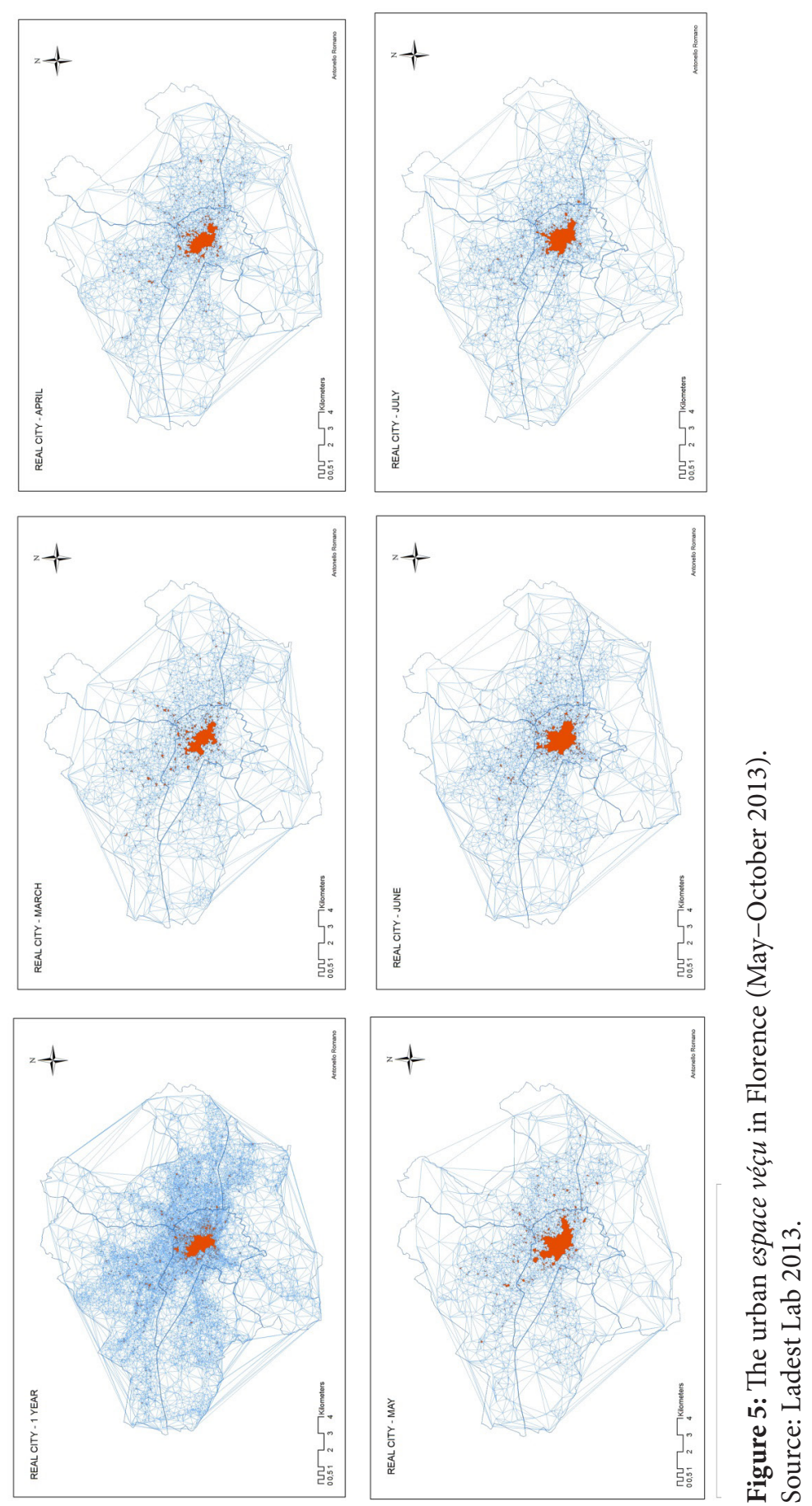


\begin{tabular}{|c|l|l|l|}
\hline Source & \multicolumn{1}{|c|}{ Sites } & \multicolumn{1}{c|}{$\begin{array}{c}\text { Comments / } \\
\text { Attributes }\end{array}$} & Meaning /process \\
\hline TripAdvisor & $\begin{array}{l}\text { Tower of London, } \\
\text { Big Ben, Tower } \\
\text { Bridge, St. Paul's } \\
\text { Cathedral, London Eye, } \\
\text { Buckingham Palace, } \\
\text { Trafalgar Square, } \\
\text { Piccadilly Circus }\end{array}$ & $\begin{array}{l}\text { Wonder, uniqueness, } \\
\text { grandeur, beauty, } \\
\text { excitement, surprise }\end{array}$ & $\begin{array}{l}\text { Tourist place } \\
\text { commodification }\end{array}$ \\
$\begin{array}{l}\text { Covent Garden, } \\
\text { Camden market }\end{array}$ & $\begin{array}{l}\text { Global imagery } \\
\text { Surtistic and folk events } \\
\text { Seighborhoods } \\
\text { (i.e.Walthamstow in } \\
\text { East London) } \\
\text { Wimbledon } \\
\text { River Thames } \\
\text { Parks }\end{array}$ & $\begin{array}{l}\text { Silence } \\
\text { Peaceful } \\
\text { Relaxing } \\
\text { Entertaining } \\
\text { Cheap }\end{array}$ & $\begin{array}{l}\text { Environmental } \\
\text { quality } \\
\text { Urban free time } \\
\text { Local community } \\
\text { life }\end{array}$ \\
\hline @Londonist & & \\
\hline
\end{tabular}

Table 2: Qualitative crowdsourced information about the London urban area.

manifestation of insiders' preferences: they reveal Londoners' desire for more intimate and less crowded places and the quest for sites where they can find better environmental quality, social ties and green areas.

\section{Conclusions}

Crowdsourced information, namely volunteered geographic information (VGI), is a revolutionary source of information for increasing spatial and behavioural knowledge on different topics or phenomena in contemporary and everyday life from politics to the environment, from cultural events to natural disasters and more. The advances in geospatial technologies in the past twenty years have enabled ordinary citizens with little formal training to participate in the production of geographic data and knowledge through diverse forms of user-generated content and VGI: everyday activities may be transformed into creative expressions that can be uploaded, modified and shared in the digital world (Sui \& Delyser 2012; Parks 2001). The multiple identities of VGI have been described as hybrid geographies which consider creative connections within geographies - physical and human, critical and analytical, qualitative and quantitative - aiming to integrate perspectives on place, revealing interactions and society at large (Sui \& DeLyser 2012: 112). From a spatial perspective, VGI is an attempt to break free 
from institutional boundaries (municipalities, regions, provinces, counties, etc.) as shown by the application of the long tail model in urban development based on VGI data (Jiang 2014) or the employment of clustering methodologies based on geolocated crowdsourced data which produce areas of diffusion of interests, emotions and conflicts. From a place perspective, places - or more traditionally regions - identified are based on people who are at or experiencing a certain place and deliver different type of information which capture social practices and ongoing processes, either peaceful or conflictual.

As with any other scientific advance, VGI provides new food for thought and has raised many epistemological questions in the field of geography (Kitchin 2013,2014) which have led to arguable definitions stating that data can speak for itself and that theory is no longer needed (Anderson 2008). But crowdsourced information is not just facts devoid of context: it may provide large quantities of geographic information which need to be distilled and exploited within clear theoretical frameworks (Kitchin 2013; Sui \& Delyser 2012). Similarly to what happened in the 19th-century when geographerexplorers needed precise measuring instruments and binoculars to record their observations of the new lands and the resultant collaboration with naturalists, surveyors and biologists, nowadays, the geographer working with VGI data needs both the computing expertise to scrape and organise data from the Web and the cognitive tools to reach the inner meaning of this information. In this scenario new alliances have emerged between geography and computing and the cognitive sciences: the tools for making good use of VGI lie in the methodologies both for geolocating the information and for qualitatively analysing the contents around which discourses and narratives can be built on different scales.

Finally, we should praise VGI and its capacity to deal both with both every day and more fundamental topics that were unreachable in the past in a timely manner and with the heterogeneity of social phenomena by locating them on the Earth's surface. There is still a great deal to do to make sense of these distributions but undoubtedly the pulse of life with all its contradictions and inequalities can be grasped through a kind of information that, although it is currently concentrated in certain countries and areas, is likely to grow rather than shrink and hopefully to become ever more inclusive.

\section{References}

Anderson, C. 2008. The end of theory: the data deluge makes the scientific method obsolete. Wired (June 23, 2008). Available at: http://www.wired.com/science/ discoveries/magazine/16-07/pb_theory (Last accessed 20 October 2014).

Aubrecht, C., Ungar, J., \& Freire, S. 2011. Exploring the potential of volunteered geo-graphic information for modeling spatio-temporal characteristics of urban population. Proceedings of 7VCT, 11: 13. 
Batty, M., Hudson-Smitha, A., Milton, R., \& Crooks, A. 2010. Map mashups, web 2.0 and the GIS revolution. Annals of GIS, (16): 1-13.

Benkler, Y., \& Nissenbaum, H. 2006. Commons-Based Peer Production and Virtue. Journal of Political Philosophy, 14(4): 394-419.

Bonney, R., Cooper, C. B., Dickinson, J., Kellin, S., Phillip, T., Rosenberg, K.V., \& Shirk, J. 2009. Citizen science: a developing tool for expanding science knowledge and scientific literacy. BioScience, 59(11): 977-984.

Boulding, K. 1956. The image: knowledge and life in societies. Michigan: Michigan University Press.

Capineri, C., \& Rondinone, A. 2011. Geografie. In volontarie. Rivista Geografica Italiana, 118: 559-577.

Castells, M. 1996. The Rise of the Network Society, The Information Age: Economy, Society and Culture. Oxford: Blackwell.

Castells, M. 2008. Communication power. Oxford: Oxford University Press.

Claval, P. 1974. La géographie et la perception de l'espace. L'espace gèographique, 39: $174-189$.

Coleman, D. J., Georgiadou, Y., \& Labonte, J. 2009. Volunteered Geographic Information: the nature and motivation of produsers. International Journal of Spatial Data Infrastructures Research, 4(1): 332-358.

Cooper, A. K., Coetzee, S., Kaczmarek, I., Kourie, D.G., Iwaniak, A., \& Kubik, T. 2011. Challenges for quality in volunteered geographical information. Retrieved at: http://researchspace.csir.co.za/dspace/bitstream/ 10204/5057/1/Cooper1_2011.pdf.

Crandall, D. J., Backstrom, L., Huttenlocher, D., \& Kleinberg, J. 2009. Mapping the world's photos. Proceedings of the 18th international conference on World wide web. ACM: pp. 761-770.

Crang, M. 1996. Envisioning Urban Histories: Bristol as Palimpsest, Postcards, and Snapshots. Environment and Planning A, 28: 429-452.

Curry, M. 1997. The digital individual and the private realm. Annals of the Association of American Geographers, 87(4): 681-699.

Curry, M. 1998. Digital Places: Living with Geographic Information Technologies. London: Routledge.

De Longueville, B., Ostländer, N., \& Keskitalo, C. 2010. Addressing vagueness in Volunteered Geographic Information (VGI)-A case study. International Journal of Spatial Data Infrastructures Research, 5: 1725-0463.

Dodge, M., \& Kitchin, R. (2013). Crowdsourced cartography: mapping experience and knowledge. Environment and Planning A, 45(1): 19-36.

Dykes, J., Purves, R., Edwardes, A., \& Wood, J. 2008. Exploring volunteered geographic information to describe place: visualization of the 'Geograph British Isles' collection. Proceedings of the GIS Research UK 16th Annual Conference GISRUK: pp. 256-267. Retrieved at: https://www.researchgate.net/ profile/Alistair_Edwardes/publication/242083251_Exploring_Volunteered_ Geographic_Information_to_Describe_Place_Visualization_of_the_ 'Geograph_British_Isles'_Collection/links/02e7e52c2862197174000000.pdf. 
Elwood, S. 2008. Volunteered geographic information: key questions, concepts and methods to guide emerging research and practice. GeoJournal, 72(3): 133-135.

Elwood, S. 2010. Geographic information science: emerging research on the societal implications of the geospatial web. Progress in Human Geography, 34(3): 349-357.

Elwood, S., Goodchild, M. F., \& Sui, D. Z. 2012. Researching volunteered geographic information: Spatial data, geographic research, and new social practice. Annals of the Association of American Geographers, 102(3): 571-590.

Girardin, F., Calabrese, F., Fiore, F. D., Ratti, C., \& Blat, J. 2008. Digital footprinting: Uncovering tourists with user-generated content. Pervasive Computing, IEEE, 7(4): 36-43.

Goodchild, M. 2007. Citizens as sensors: the world of volunteered geography. GeoJournal, 69: 211-221.

Goodchild, M., \& Li, L. 2012. Assuring the quality of volunteered geographic information. Spatial statistics, (1): 110-120.

Gouveia, C., \& Fonseca, A. 2008. New approaches to environmental monitoring: the use of ICT to explore volunteered geographic information. GeoJournal, 72(3-4): 185-197.

Graham, M. 2010. Neogeography and the palimpsests of place: web 2.0 and the construction of a virtual earth. Tijdschrift voor Economische en Sociale Geografie, 101(4): 422-436.

Graham, M., \& Shelton, T. 2013. Geography and the future of big data, big data and the future of geography. Dialogues in Human Geography, 3(3): 255-261.

Graham, M., Zook, M., \& Boulton, A. 2013. Augmented reality in urban places: contested content and the duplicity of code. Transactions of the Institute of British Geographers, 38(3): 464-479.

Graham, M., Hogan, B., Straumann, R., \& Medhat, A. 2014. Uneven Geographies of User-Generated Information: Patterns of Increasing Informational Poverty. Annals of the Association of American Geographers, 104(4): 746-764.

Graham, S. 1998. The end of geography or the explosion of place? Conceptualizing space, place and information technology. Progress in Human Geography, 22(2): 165-185.

Haklay, M. 2010. How Good is volunteered geographical information? a comparative study of OpenStreetMap and ordnance survey datasets. Environment and Planning B: Planning and Design, 37(4): 682-703.

Haklay, M. 2013a. Citizen science and volunteered geographic information: Overview and typology of participation. Crowdsourcing Geographic Knowledge. The Netherlands: Springer.

Haklay, M. 2013b. Neogeography and the delusion of democratisation. Environment and Planning A, 45(1): 55-69.

Haklay, M., Singleton, A., \& Parker, C. 2008. Web mapping 2.0: the Neogeography of the Geoweb. Geography Compass, 2(6): 2011-2039. 
Haklay, M. 2010. How good is volunteered geographical information? A comparative study of OpenStreetMap and Ordnance Survey datasets. Environment and Planning B: Planning and Design, 37(4): 682-703.

Hardy, D., Frew, J., \& Goodchild, M. 2012. Volunteered geographic information production as a spatial process. International Journal of Geographical Information Science iFirst: 1-22.

Harvey, F. 2013. To volunteer or to contribute locational information? Towards truth in labeling for crowdsourced geographic information. Crowdsourcing Geographic Knowledge. The Netherlands: Springer, pp. 31-42.

Hecht, B., \& Gergle, D. 2010. On the "Localness" of User-Generated Content, Proceedings of the 2010 ACM conference on Computer supported cooperative work. New York, NY, pp. 229-232.

Hecht, B., \& Stephens, M. 2014. A Tale of Cities: Urban Biases in Volunteered Geographic Information. In Proc. of ICWSM 2014, University of Michigan. Retrieved at http://www-users.cs.umn.edu/ bhecht/publications/bhecht_ icwsm2014_ruralurban.pdf.

Howe, J. 2008. Crowdsourcing: Why the Power of the Crowd Is Driving the Future of Business. New York: McGraw-Hill, pp. 401-408.

Hollenstein, L., \& Purves, R. 2014. Exploring place through user-generated content: Using Flickr tags to describe city cores. Journal of Spatial Information Science, (1): 21-48.

Jiang, B. (2013). The image of the city out of the underlying scaling of city artifacts or locations. Annals of the Association of American Geographers, 103(6): 1552-1566.

Jiang, B., \& Jia, T. 2011. Zipf's law for all the natural cities in the United States: a geospatial perspective. International Journal of Geographical Information Science, 25(8): 1269-1281.

Kitchin, R. 2013. Big data and human geography Opportunities, challenges and risks. Dialogues in Human Geography, 3(3): 262-267.

Kitchin, R. 2014. Big Data, new epistemologies and paradigm shifts. Big Data \& Society, 1(1). Retrieved at: http://bds.sagepub.com/content/1/1/ 2053951714528481.long (Accessed march 2016).

Levy, P. 1994. L'Intelligence collective. Pour une anthropologie du cyberespace. Paris: La Découverte.

Lussault, M. 2007. L'homme spatial: la construction sociale de l'espace humain. Paris: Seuil.

Pickles, J. 1995. Ground Truth: The Social Implications of Geographic Information Systems. New York: Guilford Press.

Poorthuis, A., \& Zook, M. 2013. Spaces of Volunteered Geographic Information. In: Adams, P., Craine, J., \& Dittmer, J. (Eds.) Ashgate Research Companion on Geographies of Media (in print).

Poorthuis, A., Zook, M., Shelton, T., Graham, M., \& Stephens, M. Using Geotagged Digital Social Data in Geographic Research. In: Clifford, N., 
French, S., Cope, M., \& Gillespie, T. (Eds.) Key Methods in Geography. London: Sage (forthcoming).

Priedhorsky, R., Masli, M., \& Terveen, L. 2010. Eliciting and focusing geographic volunteer work. ACM CSCW'10, February, Savannah: pp. 6-10.

Purves, R. S., \& Derungs, C. 2015. From space to place: place-based explorations of texts. International Journal of Humanities and Arts Computing, 9(1): 74-94.

Purves, R. S., \& Edwardes, A. J. 2008. Exploiting Volunteered Geographic Information to describe Place. Proceedings of the GIS Research UK 16th Annual Conference: pp. 252-255.

Putman, R. 1995. Bowling Alone: America's Declining Social Capital. Journal of Democracy, 6(1): 65-78.

Raffestin, C. 1988. Le rôle de la ville d'art dans l'avènement d'une économie de la contemplation. Cahiers de géographie du Québec, 32(85): 61-66.

Roche, S., Nabian, N., Kloeckl, K., \& Ratti, C. 2012. Are 'Smart Cities' Smart Enough. Global Geospatial Conference. Available at: http://www.gsdi.org/ gsdiconf/gsdi13/papers/182.pdf (Last accessed 10 October 2014).

Shelton, T., Poorthuis, A., Graham, M., \& Zook, M. 2014. Mapping the data shadows of Hurricane Sandy: Uncovering the sociospatial dimensions of 'big data'. Geoforum, 52: 167-179.

Straumann, R. K., Çöltekin, A., \& Andrienko, G. 2014. Towards (Re) Constructing Narratives from Georeferenced Photographs through Visual Analytics. The Cartographic Journal, 51(2): 152-165.

Sui, D. Z. 2004. Tobler's first law of geography: a big idea for a small world? Annals of the Association of American Geographers, 94(2): 269-277.

Sui, D., \& Delyser, D. 2013. Crossing the qualitative-quantitative chasm I: Hybrid geographies, the spatial turn, and volunteered geographic information (VGI). Progress in human geography, 36(1): 111-124.

Sui, D., Goodchild, M., \& Elwood, S. 2013. Volunteered geographic information, the exaflood, and the growing digital divide. Crowdsourcing Geographic Knowledge. The Netherlands,Springer: pp. 1-12.

Surowiecki, J. 2005. The Wisdom of Crowds. New York: Anchor.

Tapscott, D., \& Williams A. D. 2008. Wikinomics: How mass collaboration changes everything. London. Penguin.

Tobler. W. R. 1970. A computer movie simulating growth in the Detroit region, Economic Geography, 46(2): 234-240.

Turner, A. 2006. Introduction to neogeography. Sebastopol, CA: O’Reilly.

Whatmore, S. 2002. Hybrid geographies: Natures cultures spaces. London. Sage.

Wilson, M. W., \& Graham, M. 2013. Neogeography and Volunteered Geographic Information: A Conversation with Michael Goodchild and Andrew Turner. Environment \& Planning A, 45(1): 10-18.

Zook, M., \& Graham, M. 2007. The creative reconstruction of the Internet: Google and the privatization of cyberspace and DigiPlace, Geoforum, 38: 1322-1343. 